\title{
MEMÓRIA POLITICA DE JOSÉ DE RESENDE COSTA FILHO: IMAGINÁRIO DO BUROCRATA E INCONFIDÊNCIA MiNEIRA (1789-1813)
}

\author{
Wederson de Souza Gomes \\ Graduado em História pela Universidade Federal de Ouro Preto (UFOP) e mestrando \\ no Programa de pós-graduação em História (PPGHIS-UFOP).
}

wedersong@live.com

$\&$

Cláudia Maria das Graças Chaves

Doutora em História pela Universidade Federal Fluminense (UFF) - Professora Adjunta da Universidade Federal de Ouro Preto (UFOP).

claudiachavesmg@gmail.com

resumo: 0 presente trabalho analisa a atuação de José Resende Costa Filho em duas perspectivas: 1) sua participação na Inconfidência Mineira; 2) sua reinserção na administração do Império luso-brasileiro, objetivando compreender aspectos políticos, econômicos, caráter republicano e independentista da sedição mineira. Alguns autores, através dos Autos da Devassa, identificaram um projeto de Independência da América Portuguesa na sedição, todavia não havia homogeneidade de ideias entre os partícipes do movimento. O próprio Resende Costa, no ano de 1810, ainda enxergaria como necessária uma relação de complementariedade entre a colônia e Portugal. O conselheiro, nesse sentido, ainda parecia ser mais afeito às ideias regeneradoras e monárquicas.

palavras-chave: Inconfidência Mineira; Resende Costa Filho; liberdade. abstract: This paper analyzes the performance of José Resende Costa Filho in two perspectives: 1) participation in the Minas Conspiracy; 2) their reintegration in the administration of the LusoBrazilian Empire, in order to understand political, economic, republican character and independence of mining sedition. Some authors, through the Autos of Wanton, Independence identified a project of Portuguese America in the uprising, but there was homogeneity of ideas between the participants in the movement. Himself, Resende Costa, in the year 1810, still would see as required complementary relationship between the colony and Portugal. The counselor, in this sense, still seemed to be more inclined to regenerative and monarchical ideas.

keywords: Conjuration Mineira; Resende Costa Filho; freedom. 


\begin{abstract}
0 último quartel do século XVIII e as primeiras décadas do XIX representaram uma significativa transformação intelectual e estrutural nos impérios ibéricos cujos impactos desdobram-se nas áreas periféricas do sistema atlântico‥ A Inconfidência Mineira, sedição cujo cenário foi a capitania de Minas Gerais, atua com relevância nesse contexto de instabilidade das estruturas do A ntigo Regime. Reunindo clérigos, intelectuais e magistrados, a sedição questionava a autoridade metropolitana na colônia, e se consagrou como um movimento republicano em al gumas produções historiográficas ${ }^{2}$, todavia estudos mais recentes têm acrescentado novos vieses sobre os intentos da sedição?

Entreos séculos X IX eXX , a produção historiográficatratou alnconfidência Mineira como um movimento que buscava romper os laços coloniais - devido à demasiada tirania e exploração metropolitana - tendo como horizonte a independência de Minas Gerais e estendêla, posteriormente, às demais capitanias da A mérica Portuguesa4. Historiadores como Lúcio Santos, Kenneth Maxwell e Márcio Jardim são alguns dos nomes que compartilham dessa perspectiva. José Pedro Xavier da Veiga, em sua Ephemerides Mineiras, pontua que os inconfidentes buscavam combater o jugo opressor metropolitano que tanto assolava o povo mineiro, e retirava toda a riqueza da capitania.
\end{abstract}

\footnotetext{
${ }^{1}$ Istvan Jancsó aponta que essa era a posição da América Portuguesa no contexto da crise em A sedução da liberdade: cotidiano e contestação da política no final do século XVIII. In: SOUZA, Laura de Mello e (Org) e NOVAIS, Fernando A. História da Vida Privada no Brasil: Cotidiano e Vida Privada na América Portuguesa. São Paulo: Companhia das Letras, 1997, p.389.

${ }^{2}$ Lúcio Santos foi um dos primeiros autores no século XX a sistematizar uma obra sobre a Inconfidência Mineira. Em sua obra "A Inconfidência Mineira: papel de Tiradentes na Inconfidência Mineira", o autor exporia um caráter republicano e independentista da sedição.

3 João Pinto Furtado e André Rodrigues Figueiredo, através dos Autos de Sequestro, têm identificado outros aspectos da sedição mineira em usas obras.

4 Márcio Jardim afirma que os inconfidentes objetivavam a independência global da colônia, não se restringindo apenas à Capitania Mineira. A Inconfidência Mineira: uma síntese factual. Rio de Janeiro: Biblioteca do Exército, 1989, p.344.
}

GOMES, W. S. e CHAVES, C. M. G. Memória política de josé de resende Casta Filno: ímašinário do burocrata e Fnconfidêneia wineira (1789-1813). albuquerque: revista de historia. vol. 9, n. 17, jan.-jul. de $2017, \mathrm{p} \cdot 270-285$. 
A pesar de o movimento ter sido duramente reprimido pela Coroa Portuguesa, e nos primeiros anos do Império do Brasil referências ao movimento terem sido deixadas de lado, com a criação do Instituto Histórico e Geográfico Brasileiro, já no Segundo Reinado, a figura de um dos inconfidentes ganharia contornos heroico.J osé de Resende Costa, o filho, tornar-se-ia, no ano de 1839, sócio correspondente do IH GB e, posteriormente, seria condecorado membro honorário no ano de 1840. J unto de sua con decoração viria um convite para escrever um relato acerca da sedição.

Nesse contexto ocorre uma retomada da sedição mineira como fato relevante para a história do Brasil e, Resende Costa Filho, partícipe e representante vivo seria primordial para a consolidação de uma memórialibertária do movimento, sem, contudo, abordar um antagonismo à Coroa Portuguesa. Como expõe Manoel Luís Sal gado Guimarães, a criação do IH GB viabilizou a possibilidade de se pensar e consolidar a história brasileira de uma forma sistematizada. U ma vez implantado - Estado N acional, impunha-se a tarefa do delineamento de um perfil para a "Nação brasileira" ${ }^{\text {. }}$. A proposta, segundo Guimarães, era garantir uma identidade própria perante as demais "nações", buscando construír uma nação continuadora do processo civilizatório português, sendo sua inspiração um patriotismo desvinculado de qualquer espécie de ódio.

As narrativas posteriores à Independência apresentavam os inconfidentes como homens corajosos que foram condenados equivocadamente pela Coroa Portuguesa. 0 que pode ser apercebido é a construção de um "mito" em volta da Inconfidência Mineira com acréscimos e atribuições que não representavam necessariamente o real projeto dos envolvidos. Por meio dessas narrativas surgem as primeiras tentativas de se associar a formação de um ideário de nação brasileira a movimentos políticos do período colonial como a Inconfidência, bem como a ligação direta desses eventos com o processo de emancipação política brasileira no início do século XIX.

Isso fica mais evidente ao analisarmos as falas do panegírico Thomaz José Pinto Serqueira, em sua referência aos membros que faleceram no ano de 1841, deixando clara sua predileção pela imagem e importância de Resende Costa:

Indiferente, pois seria, Senhores, que para o breve esboço, que tenho de traçar, eu começasse por um ou por outro dos nossos consócios falecidos, todavia creio que ninguém me culpará se dentre todos der mui deliberadamente preferência ao Sr. Conselheiro J osé de Resende Costa, esirvam de título desta minha escolha os padecimentos, que ainda no verdor de seus anos teve

\footnotetext{
5 GUIMARAES, Manoel Luis Salgado. Nação e Civilização nos Trópicos: o Instituto Histórico Geográfico Brasileiro e o projeto de uma história nacional. Rio de Janeiro. Estudos Históricos, $\mathrm{n}^{\circ}$ 1, 1998, p.6.

GOMES, W. S. e CHAVES, C. M. G. Memória palítica de josé de Resende Casta Filna: i̇mašinário do burocrata e Fnconfidência Mineira (1789-1813). albuquerque: revista de historia. vol. 9, n. 17, jan.-jul. de $2017, \mathrm{p} \cdot 270-285$.
} 
de sofrer por sua querida pátria.'.... Em vez de louros esses homens só colheram a palma do martírio: e o Senhor Conselheiro J osé de Resende Costa foi um daqueles que mais tevequecontar; earazão fácil é de saber:era daqueleque melhor partea execução.Quiseram infamalo, e para isso de companhia com seu pai o fizeram andar em roda do patíbulo. Como não pal pitaria esse coração por ver que em vez da ventura da pátria só tinha conseguido demorala mais? $\mathrm{N}$ ão pela infâmia da pena; que bem sabia ele que ganhava honra imortal, e que a posteridade havia de julgar entre ele seus julgadores, e que a decisão havia de ser em seu favor; sabia que o Brasil havia deser um dia nação soberana; e que então, senão antes, esse mesmo Brasil o havia de honrar ou a sua memória.

Resende Costa, o filho, abdicou de uma memória sobre a Inconfidência Mineira e os objetivos nela contidos oferecendo ao IH GB uma tradução de um artigo do historiador Robert Southey sobre a sedição e, com a colaboração do padre Manoel Rodrigues da Costa, incluiu algumas correções e aditamentos ao artigo. A abdicação do conselheiro foi relevante para pensar uma questão: Por que Resende Costa Filho, testemunha ocular dos fatos, se recusou a escrever uma memória sobre a Inconfidência Mineira? No momento do convite o burocrata argumentou estar demasiadamente velho e doente para tal, porém, analisando parte de sua trajetória política, foi possível inferir outros elementos que podem explicar a recusa.

Para desenvolver essa ideia al guns pontos são primordiais a serem abordados, sendo eles, o uso do passado, a verdade, e o aprendizado através da história. Hans Ulrich Gumbrecht ressalta que a historiografia continua defendendo a capacidade da história de ensinar, pois é o elemento legitimador da disciplina como conhecimento científico. Contudo, no cotidiano, poucas pessoas recorrem ao conhecimento histórico para questões práticas. Isso, segundo o autor, é o final de um processo de progressiva perda da capacidade orientadora da história?.

A proposta de Gumbrecht é interessante para pensarmos a amplitude assumida pela literatura, artes, TV e outras mídias na apreensão do passado. N os últimos meses, a novela Liberdade Liberdade produzida pela Rede Globo, cuja história se passa entre os fins do século X VIII e início do XIX - tendo como temas a Inconfidência Mineira e vinda da Família Real para o Brasil - é um exemplo interessante. A novela obteve relativo sucesso, sendo bastante comentada e discutida nas redes sociais. Uma trama ficcional, desenvolvida a partir de um

\footnotetext{
${ }^{6}$ SERQUEIRA, Thomaz José de Pinto. 1841. “Elogio histórico dos membros do Instituto falecidos no terceiro ano acadêmico”, 1841. RIHGB, Rio de Janeiro, TOMO III, p. 540-545.

7 GUMBRECHT, Hans Ulrich. Depois de depois de aprender com a história. In: NICOLAZZI, Fernando; MOLLO, Helena M.; ARAUJO, Valdei L. (Orgs.). Aprender com a história? O passado e o futuro de uma questão. Rio de Janeiro: Editora FGV, 2010, p. 26.
}

GOMES, W. S. e CHAVES, C. M. G. Memóría palítica de Jasé de resende Casta Filna: inaśinário do burocrata e Inconfidência mineira (1789-1813). albuquerque: revista de historia. vol. 9, n. 17, jan.-jul. de $2017, \mathrm{p} \cdot 270-285$. 
acontecimento histórico famoso da memória nacional e também da história da historiografia brasileira, que sedimenta o imaginário libertário unívoco da sedição mineira. A ssim como nos manuais didáticos e na memória popular Tiradentes é alçado a herói e líder do movimento.

$\mathrm{N}$ ão é o propósito negar as ideias de liberdade contidas no movimento, os inconfidentes ansiavam autonomia política e econômica, todavia é preciso que esse ensejo seja ponderado. Quando nos referimos à liberdade econômica e política, consideramos o fato de que as ideias liberais propagadas pelo iluminismo ainda estavam em processo fosse à Europa, fosse ao continente americano. Diferente de um projeto liberal que contemplasse o livre mercado e o capital, 0 anseio de al guns sediciosos era por autonomia para gerir a política administrativa ${ }^{8}$ da capitania mineira. Pensando assim, observemos o relato de Resende Costa, o pai;

Passando por casa dele Respondente o Sargento-M or Luís V az de Toledo, irmão do dito vigário de São J osé, Ihe disse que seu irmão, dito V igário, já não ia para Portugal; porquanto estava tratando-se fazer na Capitania de Minas uma sublevação, e levante, no qual entrava o dito V igário, Carlos Correia de Toledo.[.] Respondeu, que o fim, que o dito Luís $V$ az Ihe disse, que se propunham conseguir com a dita sublevação, era o de conseguirem liberdade, estabelecendo várias Repúblicas na dita Capitania, como também uma Universidade semelhante à de Coimbra, pelo que ficava escusado mandar ele Respondente seu filho para Portugal. [.] E ficando senhores da terra, perdoariam todos os devedores à Fazenda Real tudo o que devessem; e ficariam os dízimos aos vigários; e que o ouro correria a quinze tostões; e que o concurso que cada um prestava para a dita sublevação só ele Respondente ouviu dizer ao dito Luís $V$ az, que as leis pelas quais se havia de reger a nova República, estavam a cargo do desembargador Tomás A ntônio Gonzaga, e do coronel Inácio J osé de Alvarenga; porém que ele Respondente não deixou de mandar seu filho para Coimbra, esperando pelaU niversidade, quese havia deestabelecer, mas sim, porque lhe faltaram os meios de lá o poder manter 9 .

\footnotetext{
8 João Pinto Furtado acredita que sobre as relações econômicas além das fronteiras da colônia ainda é difícil afirmar, por exemplo, que houvesse ligações comerciais sólidas entre cariocas e mineiros. Nessa mesma perspectiva torna-se problemático asseverar apoios externos fosse ao plano estrangeiro ou com outras capitanias. FURTADO, João Pinto. O Manto de Penélope: história, mito e memória da Inconfidência Mineira de 1788-9. São Paulo: Companhia das Letras, 2002, p. 146-147.
}

${ }^{9}$ Autos da Devassa da Inconfidência Mineira, v.5, pp.439-440. Disponível em: <http://portaldainconfidencia.iof.mg.gov.br/leitura/web/v5?p\#>

GOMES, W. S. e CHAVES, C. M. G. Memória política de josé de resende Casta Filna: inaśinário do buracrata e Fnconfidência Mineira (1789-1813). albuquerque: revista de histaria. vol. 9, n. 17, jan.-jul. de $2017, \mathrm{p} \cdot 270-285$. 
Um exame cuidadoso sobre as falas de Resende Costa revelam traços que por vezes passaram despercebidos ou foram interpretados de maneira equivocada por parte da historiografia. 0 patriarca enfatiza a pretensão de enviar seu filho para aU niversidade deCoi mbra, contudo com o sucesso da "dita sublevação" não haveria mais a necessidade, pois seria criada uma universidade semel hante àquela que havia em Portugal. Resende Costa, o pai, usa um argumento retórico em sua defesa, mas discretamente revela seu real intento, o perdão das dívidas junto à Real Fazenda.

O oligarca era um homem de posses consideráveis, e teve sequestrado pela devassa uma morada de casas, 31 escravos, cinco utensílios minerais, 245 datas de exploração mineral e dez obrigações creditícias que, avaliadas, somavam 333\$461 rés $^{10}$. Como minerador e parte da elite mineira devia ter interesses maiores com a sedição do que apenas a partida de seu filho para Coimbra. A Resende Costa faltava recursos financeiros para enviar o filho a Coimbra, ademais suas dívidas ultrapassavam seus créditos. A imposição da derrama significaria para ele, assim como para outros inconfidentes, um aprofundamento em dívidas'11.

Podemos inferir com seu relato que ele tenta amenizar a ideia de que cometera traição, buscando apenas uma resolução mais fácil para os interesses intelectuais aspirados por seu filho ${ }^{12}$. A lgo bastante controverso se pensarmos que consolidada a sedição ainda levaria um tempo significativo até que fosse constituída uma Universidade semelhante à de Coimbra na capitania mineira. Portanto, não haveria tempo hábil para que o jovem Resende Costa pudesse ingressar na instituição. Por outro lado, com o sucesso da sedição, uma mudança tributária sobre a taxação do ouro e o perdão das dívidas ben eficiaria oligarca substantivamente.

Kenneth Maxwell pondera que a crise aurífera impôs à capitania mineira profunda dificuldade para arrecadação do quinto real. A partir da década de 1760, a capitania não conseguia mais arrecadar as 100 arrobas exigidas pela Coroa Portuguesa. A escassez de ouro também foi responsável pelo deslocamento

\footnotetext{
10 Seu irmão e sócio nos projetos de mineração era o maior de seus devedores, o capitão Antônio Nunes de Resende, com 58,91\% de todos os rendimentos a receber que tinha direito (196\$436 réis). Apesar de Resende Costa, o pai, possuir dez créditos a receber, os valores de suas dívidas eram maiores, como informa Rodrigues. RODRIGUES, André Figueiredo. A família Resende Costa e seu envolvimento na Inconfidência Mineira: patrimônio e estratégias familiares para burlar a Coroa Portuguesa (Minas Gerais, 1789-1804). São Paulo, Anais do XXVI Simpósio Nacional de História - ANPUH, 2011, p. 3.

${ }^{11}$ Rodrigues narra que o português Severino Ribeiro, cunhado de Resende Costa, o pai, foi o responsável por pagamentos de empréstimos e compras de fazendas do inconfidente por quatro vezes, sendo a primeira delas em 24 de novembro 1765. Outro credor do patriarca da família Costa foi Gervásio Pereira Alvim, que com a devassa tornou-se responsável por administrar, como fiel depositário, os bens apreendidos pela devassa. Rodrigues acredita que Resende Costa, na eminência de ser preso juntamente de seu filho e com idade bastante avançada, negociou o matrimônio de sua filha com Gervásio e em certa forma isso evitou a perda total de seus bens sequestrados. In: RODRIGUES, André Figueiredo. Ibidem, p. 4.

12 O jovem Resende Costa, assim como o pai, em sua inquirição destaca o desejo de ingressar em Coimbra, mas que devido a falta de recursos, seu pai não poderia enviá-lo.
}

GOMES, W. S. e CHAVS, C. M. G. Memória palítica de Jasé de resende Casta Filna: inasinário do burocrata e Fnconfidência Mineira (1789-1813). albuquerque: revista de historia. vol. 9, n. 17, jan.-jul. de $2017, \mathrm{p} \cdot 270-285$. 
econômico para a região Sul da capitania e, por conseguinte, acuidade das atividades agrícolas e pastoris. A crise aurífera associada à ascensão de Martinho de Melo e Castro como novo ministro da Rainha Marial imprimiu aos mineiros um contexto bastante diferenciado, e estes se viram diante da reiteração das imposições metropolitanas e as obrigações coloniais.

Os oligarcas mineiros participavam de uma miríade de atividades econômicas "e estavam crescentemente vinculados à economia regional de um modo que jamais poderiam estar os grandes produtores de matérias coloniais das demais zonas da A mérica Portuguesa"13. Tomando como exemplo a Junta da Fazenda, Maxwell expõe que esta não era desafiada por qualquer autoridade de nível idêntico. V ila Rica não tinha relação ou alfandega independente, como as existentes nas capitanias litorâneas, com jurisdições definidas. A J unta da Fazenda de Minas atuava como um órgão no qual eram centralizados os mais poderosos interesses econômicos locais. A plutocracia mineira, que durante a gestão pombalina ${ }^{14}$ construiu forte imbricação entre os seus interesses e o da administração local, assistiram a um estrangulamento de suas ambições.

Esse traço marcante da autonomia mineira ficou marcado nas produções do século XIX como um "caráter mineiro". Uma concepção que estava atrelada à destacada relação com o poder central, e nos aspectos de formação econômica, social e religiosa da colônia ${ }^{15}$. Havia uma tendência política das elites mineiras, como rebeldes e insubordinados ${ }^{16}$, tangenciando uma discussão acerca da própria geografia da região que se confundia, por vezes, com a história dos motins antifiscai $s^{17}$. U ma visão, em certa medida, bastante niveladora das distintas ten dências políticas existentes na capitania18.

\footnotetext{
${ }^{13}$ Kenneth Maxwell. MAXWELL, Kenneth R. As Causas e o Contexto da Conjuração Mineira. In: FURTADO, Júnia F. (org), Diálogos Oceânicos: Minas Gerais e as novas abordagens para uma história do Império Ultramarino Português. Belo Horizonte: Ed.UFMG, 2001, p.396.

14 Maxwell aborda que durante a gestão pombalina, os membros da capitania mineira conquistaram relevante autonomia. Pombal, segundo Maxwell, não tinha objeções a uma aproximação entre a América Portuguesa e a Inglaterra. Melo e Castro, ao contrário, tenderia para uma relação com o continente europeu. Ibidem, p.391.
}

${ }^{15}$ Ana Rosa Cloclet apresenta que a autonomia, insubordinação e conflitos caracterizaram aquilo que a historiografia convencionou definir como o "caráter dos mineiros". SILVA, Ana Rosa Cloclet. Identidades políticas e a emergência do Novo Estado Nacional: o caso mineiro. In: Independência: história e historiografia. São Paulo: Hucitec, 2005, p.518.

16 SOUZA, Laura de Mello e. Norma e conflito: aspectos da história de Minas no século XVIII. Belo Horizonte: Editora UFMG, 2006, p.102.

17 FIGUEIREDO, Luciano Raposo de Almeida. O Império em Apuros: Notas para o estudo das alterações Ultramarinas e das práticas políticas no Império Colonial Português, séculos XVII e XVIII. In: Diálogos Oceânicos: Minas Gerais e as Novas abordagens para uma história do Império Ultramarino Português, pp. 197-254.

${ }^{18}$ SILVA, Ana Rosa Cloclet, op. cit., p.519.

GOMES, W. S. e CHAVS, C. M. G. Memória palítica de Jasé de resende Casta Filina: inaśinário do buracrata e Fnconfidência Mineira (1789-1813). albuquerque: revista de historia. vol. 9, n. 17, jan.-jul. de $2017, \mathrm{p} .270-285$. 
A cerca da criação de uma república, outro ponto do relato de Resende Costa, João Pinto Furtado traz considerações relevantes para pensarmos o ideário republicano mineiro. $\bigcirc$ autor destaca que "os acontecimentos que resultaram na formação dos Estados Unidos da A mérica eram relativamente bem conhecidos e ensejavam acalorados debates"19. Todavia, o autor sugere cuidado ao considerar os conflitos coloniais como projeto de república representativa, pois considera que a ideia era ainda um ensaio e uma intenção, mesmo para os ingleses. Furtado enfatiza que a imagem de república ensejada pelos inconfidentes tenderia a ser alimentada pelas teorias de Montesquieu, que ao contrário dos americanos do $\mathrm{N}$ orte, tinham John Locke como referência teórica indiscutível.

Segundo Furtado, Montesquieu, um dos teóricos que esteve presente na biblioteca da família de Resende Costa e do cônego Luís Vieira, entendia que a República precisava de uma expressão territorial modesta, havendo relativa igualdade, as leis deveriam ser expressas através da vontade popular, e o bem do Estado deveria antepor o interesse particular ${ }^{20}$. A pesar desses traços presentes na obra de M ontesquieu, o modelo republicano estava ancorado em tradições ibéricas e latinas. Em alguns aspectos o modelo republicano dos inconfidentes distanciavase do ideário que se delineava na A mérica do N orte.

A abolição da escravidão também era um entrave entre os sediciosos. Não era coesa entre os Inconfidentes a possibilidade de abolição da escravatura, tendo dissonância entre pequenos e grandes proprietários sobre a possibilidade. "Proprietários de 36\% da massa escrava sequestrada estavam dispostos a transgredir sua condição de proprietários, ao passo que apenas $4 \%$ da mesma massa eram terminantemente contrários"21.

A pesar de inseridos na cultura iluminista que defendia a liberdade da vida, do indivíduo e da propriedade, os inconfidentes não contemplavam o fim do sistema escravista, por considerálo necessário à manutenção da capitania. Também acreditavam que deveria ser vedado o acesso ao sistema de representação parlamentar àqueles que recebessem algum tipo de renda do Estado. $O$ alferes Joaquim José da Silva $X$ avier, mesmo tendo entrado para a história como protomártir da liberdade e democracia, estava mais próximo às crenças do A ntigo Regime português, al gumas as quais val orizava e pretendia restaurar ${ }^{22}$.

Retomemos, portanto, o argumento de Gumbrecht sobre a perda do caráter orientador que assola a história para pensarmos os pontos expostos anteriormente.

\footnotetext{
${ }^{19}$ FURTADO, João Pinto. op. cit., p. 20.

${ }^{20}$ FURTADO, João Pinto. op. cit., p..154 et seq.

${ }^{21}$ RODRIGUES, André Figueiredo. A Fortuna dos Inconfidentes: caminhos e descaminhos dos bens de conjurados mineiros (1760-1850). São Paulo: Editora Globo, 2010, p.46-47.
}

${ }^{22}$ FURTADO, João Pinto. op. cit., p.21-22. 
A novela amarra à Inconfidência a ideia de Liberdade e o reforça, pois o vocábulo se repete no título. A história tem como protagonista a filha de Tiradentes, J oaquina, que no decorrer da narrativa se volta contra o jugo opressor da administração portuguesa no Brasil. Produzindo, dessa forma, uma noção de continuidade, de um projeto abortado e que precisava ser concluído. A demais, imprimem à sedição mineira um traço social popular, como se observa na sinopse do colunista e crítico televisivo N ilson X avier sobre a protagonista Rosa/J oaquina. "É no Brasil que ela se confronta com sua história ao descobrir mais sobre o pai biológico, sobre os inconfidentes, sobre as diferenças sociais e as agressões aos menos afortunados ocorridas neste país"23.

Com a novela global, assistimos a um fal seamento da Inconfidência Mineira, e o passado servindo como fonte de entretenimento. Vinculam à memória de Tiradentes um projeto inacabado que tentou combater injustiças contra a sociedade. U ma nova história do movimento mineiro adentra a casa de inúmeros brasileiros e reproduz de maneira unívoca uma capitania mineira contrária às injustiças e imposições da Corte portuguesa; agora devidamente instalada no Rio de J aneiro. 0 falseamento énecessário, trata-se deteledramaturgia e como salientado por Caroline Silveira Bauer e Fernando N icolazzi, se "escrever a verdade requer sacrifícios para o historiador, ao escritor satírico e autor do que se pode chamar de ficção é concedida a licença para mentir, desde que mantidas com considerável grau de plausibilidade e verossimilhança"24.

Mais interessante sobre esse fato é que, mesmo sendo um movimento de elite com tímida participação de camadas mais baixas, por um longo período, aos sediciosos mineiros, era associada a ideia de uma luta por toda a sociedade, mais especificamente uma luta pela libertação da nação brasileira. A novela não se constrói em sintonia com os novos vieses historiográficos, mas é plausível, pois está avizinhada do registro verdadeiro. Nesse caso, embasada em antigas teses historiográficas de que a inconfidência seria um movimento nativista precursor da história nacional brasileira.

Como assevera Rogério Forastieri da Silva, ${ }^{25}$ o nativismo como precedente do nacionalismo vem sendo apresentado constantemente nas análises historiográficas, tendo em vista que havia de se buscar no passado o presente da nação. Conceituar o nativismo, entretanto, é al go bastante movediço, já que não há uniformidade no uso do conceito. No contexto do IH GB, a nação brasileira já existia

\footnotetext{
${ }^{23}$ XAVIER, Nilson. Disponível em <http://www.teledramaturgia.com.br/liberdade-liberdade/>.

${ }^{24}$ NICOLAZZI, Fernando Felizardo; BAUER, Caroline Silveira. O historiador e o falsário: Usos públicos do passado e alguns marcos da cultura histórica contemporânea. Varia Historia. Belo Horizonte, vol. 32, n. 60, 2016, p. 810.

${ }^{25}$ O historiador aborda, em sua obra Colônia e Nativismo: A história como biografia da nação, as fronteiras do conceito de nativismo e elenca diferentes ocorrências e autores que discursaram sobre o assunto. Ver: Colônia e Nativismo: A história como biografia da nação. São Paulo: Editora Hucitec LTDA, 1997.
}

GOMES, W. S. e CHAVS, C. M. G. Memória palítica de Jasé de resende Casta Filna: irmaśinário do burocrata e Fnconfidência wineira (1789-1813). albuquerque: revista de historia. vol. 9, n. 17, jan.-jul. de $2017, \mathrm{p} .270-285$. 
desde períodos imemoriais e por isso os eventos do passado colonial constituíam um nexo com a emancipação política.

François $\mathrm{H} \operatorname{artog}^{26}$, em sua tentativa de conceituar as novas experiências de tempo e escrita da história desenvolveu uma questão pertinente à discussão que vem sendo empreendida nesse trabalho. Mas o que é ou pode ser uma história nacional? E explica que por algum tempo os historiadores acharam que estavam livres desse problema, a não ser que escrevessem manuais escolares. Como escreveríamos história nacional, sem reativar os padrões da historiografia do século X IX , ou seja, com a estreita associação de progresso enação (a nação como progresso e a história como progresso da nação), ou sem apresentar a nação como um paraíso perdido?

Liberdade Liberdade está longe de ser um trabalho historiográfico, mas explicita teorias que circundaram a H istoriografia Brasileira dos séculos XIX eXX, reativando-as para produzir algo que se aproxime do imaginário do espectador comum. A Inconfidência teria, em potência, os genes da nação brasileira. A novela, mesmo que de maneira despretensiosa, também reafirma que a verdade não éuma especificidade que os historiadores têm sob seu poder. 0 jornalismo ou a dramaturgia são capazes de produzir verdade, sem necessariamente produzir factualidade ${ }^{27}$. A novela global conseguiu relativo sucesso exatamente por reativar um fato conhecido da memória nacional e mesclar com doses de romance e ficção. O sucesso da novela mostra que o fascínio pelo passado éforte e se apresenta como convite para que a historiografia continue a pensar formas de atrair o leitor leigo.

\section{luso-brasileiro.}

0 retorno de Resende Costa Filho ao Brasil e sua atuação no Império

A nalisadas as abordagens a respeito dos horizontes que moviam os sediciosos, e elencadas as condições em que estava imersa a capitania mineira no último quartel do século XVIII, discutiremos o caráter restaurador do movimento a partir da trajetória política de Resende Costa, o filho. Propomos também, através de uma documentação ainda não explorada, asseverar a ausência de um plano comum a todos os membros da sedição. 0 intento é apontar, parcialmente, alguns dos elementos que podem ter levado o intelectual a abdicar de um relato próprio acerca da Inconfidência Mineira.

0 jovem, que aos 27 anos tinha como destino a morte por enforcamento juntamente de seu pai ${ }^{28}$, conseguiria o perdão Real, tendo sua sentença comutada

\footnotetext{
${ }^{26}$ HARTOG, François. Tempo, História e a escrita da história: a ordem do tempo. Revista da História. São Paulo, 2003, p.33.

${ }^{27}$ Para pensar o trabalho foram contempladas as discussões e apontamentos desenvolvidos no curso acerca da relação do historiador e a verdade.

28 Jardim, Márcio. A Inconfidência Mineira: uma síntese factual. Rio de Janeiro: Biblioteca do Exército, 1989 , p.344.
}

GOMES, W. S. e CHAVE, C. M. G. Memória política de Jasé de resende Casta Filna: inaśinário do burocrata e Fnconfidência Mineira (1789-1813). albuquerque: revista de historia. val. 9, n. 17, jan.-jul. de 2017, p. 270-285. 
em degredo por 10 anos para a Á frica, na ilha de São Tiago de Cabo V erde. Resende Costa Filho atuou na administração fazendária na colônia durante o período do degredo entre os anos de 1792 e 1803. Em 1803 requereu licença para mudar-se para Lisboa, pois esperava contar com o apoio do amigo, Manoel Jacinto Nogueira da Gama, na casa de quem se hospedou. Em Portugal, foi nomeado escriturário do Erário Régio no ano de 1804 e em 1809, com o príncipe D. João já no Brasil, foi chamado enomeado para cuidar de tudo que era relativo à administração da Fábrica de Lapidação dos diamantes, chegando depois a ser contador geral do Erário e posteriormente escrivão da mesa do tesouro. Função que desempenhou até o ano de 1827, também foi eleito deputado por Minas Gerais para a Assembleia Constituinte de 1823 e na primeira Legislatura em 1826 . No ano de 1827 recebeu 0 título de Conselheiro, por D. Pedro I, e em 1839 viria a integrar o seleto grupo de membros do Instituto Histórico e Geográfico Brasileiro.

0 breve resumo da atuação de Resende Costa Filho no degredo e, posteriormente em Portugal, serve de subsídio para que iniciemos a análise de sua relação com a monarquia e a soberania portuguesa. Com base na destacada carreira política que construiu e as relações que estabelecera estando em Portugal, é possível entrever o imaginário de Resende Costa Filho. É válido salientar que os A utos da Devassa evidenciam deforma comedida seus objetivos ede seu progenitor. Resende Filho, mesmo que sob pátrio poder do pai, aparentava ter conhecimento dos problemas econômicos que a família enfrentava, ele também salienta a ausência de meios de seu patriarca assisti-lo na Universidade ${ }^{29}$. Isso, em nossa compreensão, avigora a ideia de que os inconfidentes necessitavam de uma resposta imediata aos seus problemas, e com isso restaurar uma ordem anterior.

As forças metropolitanas e os laços coloniais se viam ameaçados em decorrência de uma conscientização dos súditos, que não aceitariam passivamente as duras medidas que estariam por vir ${ }^{30}$. Embora alguns inconfidentes fossem movidos por elevadas políticas reformadoras, para outros, e não poucos, o objetivo da inconfidência era apenas a suspensão da derrama efetivamente obtida em 14 de março de 1789. Como afirma Furtado, a derrama, para al guns dos inconfidentes não seria um pretexto e sim o motivo ${ }^{31}$. A suspensão da derrama levou a um enfraquecimento da sedição antes mesmo da repressão que se abateu sobre os

\footnotetext{
29 Autos da Devassa da Inconfidência Mineira, v. 5, p. 450. Disponível em: <http://portaldainconfidencia.iof.mg.gov.br/leitura/web/v5?p\#>

${ }^{30}$ Maxwell destaca que os inconfidentes esperavam que a derrama fosse imposta em meados de fevereiro. Contando com a inquietação geral do povo e conivência dos dragões, seria instigado o motim. MAXWELL, Kenneth R. op. cit., p.402.

31 FURTADO, João Pinto. A Inconfidência Mineira: um novo tempo ou reedição dos motins do Antigo Regime? In: RESENDE, Maria Efigênia Lage de e VILLALTA, Luiz Carlos (Orgs.). História de Minas Gerais: as Minas setecentistas. Belo Horizonte: Autentica; Companhia Tempo, 2007. v. 2, p. 640
}

GOMES, W. S. e CHAVE, C. M. G. Memória política de Jasé de resende Casta Filno: inaśinário do burocrata e Inconfidência mineira (1789-1813). albuquerque: revista de historia. val. 9, n. 17, jan.-jul. de 2017, p. 270-285. 
inconfidentes, apenas a partir de maio de $1789^{32}$. Os sediciosos foram presos e acusados de lesa-majestade, todavia apenas Tiradentes deveria ser enforcado - 0 mentor e líder do movimento - e os demais sofreriam degredo e penas diferenciadas.

Cumprindo sua pena entre os anos de 1792 e 1803, Resende Costa, o filho, além das funções desempenhadas na África ${ }^{33}$ e Lisboa, retornou ao cerne da administração do Império luso-brasileiro em um cargo de extrema confiança. Como apontando pelo próprio Resende Costa em sua Memória H istórica dos Diamantes, onde ele relata que

Creou-se no Real Erario huma repartição separada debaixo da inspeção da Mesa do mesmo, no qual se tratassem os negócios relativos a diamantes, a Portugal e Inglaterra, de que fui encarregado. Por Decreto de 8 de junho de 1812 e Instrucções que 0 acompanharão, se determinou construir-se em hum lugar contíguo à Casa da M oeda a fabrica de lapidar diamantes ${ }^{34}$.

Essa reinserção de Resende Costa na administração Imperial, após acusação do crime de lesa-majestade, tem dois dados importantes a serem ressaltados. Um primeiro fator é a dinâmica das relações no Império luso-brasileiro; o segundo é a tensão que se estabelece com a crise do A ntigo Regime.

É inegável que o sistema colonial passava por uma transformação em suas estruturas, e a vinda da Família Real para a A mérica portuguesa mudou a dinâmica da estrutura colonial. Mas novamente reforçamos, existia uma crise, ou seja, uma dissensão em alguns dos padrões convencionais das sociedades ibéricas, porém outras transformações aconteciam de maneira gradativa. "Dito em outras palavras, isso significa que a crise é a condição necessária, mas não suficiente para a mudança”35. Os acontecimentos na França promoveram uma verdadeira demolição

\footnotetext{
320 autor tem a premissa de que o ideário da independência das treze colônias teve relevância na difusão de possibilidades e um novo contexto para a capitania. Concomitante a isso, em 1789, acontecia a Revolução na França e que, se pensada dentro de suas especificidades, ainda não possuía a consciência e o caráter glorioso com o qual foi consagrado. Esse é um traço importante para pensarmos a repressão sofrida pelos inconfidentes, pois desde outubro de 1789 sabiam que a família real francesa estava sob o poder dos revolucionários. Diferentemente da inconfidência de Curvelo, e mesmo contendo membros importantes da elite e clérigos, a Inconfidência Mineira foi tratada com muito mais rigor, pois as notícias dos eventos na França mostravam que os limites da Monarquia estavam ameaçados. FURTADO, João Pinto. op. cit., p.72.

${ }^{33}$ Durante o degredo, mesmo exilado, os inconfidentes atuavam em interesses da Coroa.

34 COSTA, José de Rezende. Memória Histórica dos Diamantes. Rio de Janeiro: Typ Imperial e Constitucional de J. Villeneuve E C, 1836, pp.27.

35 SILVA, Rogério Forastieri Da. Colônia e Nativismo: a história como biografia da nação. São Paulo: Editora Hucitec, 1997, p.21.
}

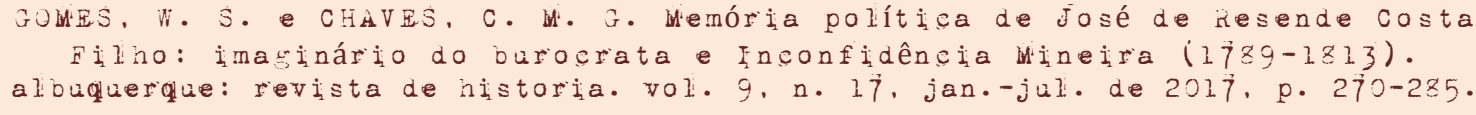


das estruturas. 0 regime absolutista encontrava-se fragilizado diante dos novos ventos que sopravam. U ma mudança nas relações sociais fazia-se necessária para a sobrevivência de um sistema queruía. E com esseviés interpretamos as novas ações adotadas pela Coroa Portuguesa, na figura de d. Rodrigo de Sousa Coutinho, que ingressou no governo do Príncipe Regente, D.J oão V I, no ano de 1796, na condição de Ministro do Ultramar e da Marinha.

Formado no cerne da ilustração, d. Rodrigo - Conde de Linhares -, compartilhava, junto de outros estadistas, sua visão sobre os problemas estruturais que assolavam Portugal e tratava seu envolvimento no compasso das reformas estruturais processadas em outros países europeus ${ }^{36}$. 0 Conde de Linhares, afilhado de Pombal, de quem teve direta orientação, empreendeu alterações nas políticas imperiais tal como o modelo pombalino. Seu empenho consistia em proporcionar ao Brasil autonomia econômica, o que não significava, necessariamente, um projeto independentista ${ }^{37}$.

Resende Costa Filho estabeleceu ótima relação com a família Sousa Coutinho, tendo trocado correspondências pessoais com os irmãos do Conde de Linhares, a Dona Mariana de Sousa Coutinho, o Principal de Sousa - José A ntónio de Meneses de Sousa Coutinho -, e Dona Maria Balbina. Em correspondência enviada à Dona Mariana, no ano de 1813 , Resende Costa demonstra seu bom relacionamento com aquela família.

Peço a V ossa Excelência para fazer agradecer da minha parte ao Senhor Comendador Silva o retrato do grande Senhor Conde de Linhares; não me podia fazer hum mesmo de mais valor, equeeu mais lhe agradeça: Tinha já hum que eu tinha herdado a Excelentíssima Senhora Condessa de Linhares; dos dois, hum vou mandar a minha irmã em Minas Gerais, e recomendar-Ihe a hum ao seu filho primogênito, para que conserve o retrato do maior homem que tinha a Nação, o Protetor do Brasil e modelo de patriotismo 38.

A citação acima corrobora não apenas os laços queo Conselheiro estabelecera com os Sousa Coutinho, como também mostra a sua visão de patriotismo. FrançoisX avier Guerra, ao analisar os conceitos de pátria e nação durante o século X VIII,

\footnotetext{
36 SILVA, Ana Rosa Cloclet. Inventando a Nação: intelectuais ilustrados e estadistas luso-brasileiros na crise do Antigo Regime (1750-1822). São Paulo: Editora Hucitec, 1971.

37 PAIM, Antonio. A Corte no Brasil. D. Rodrigo de Sousa Coutinho. São João del-Rei. Revista de Estufos Filosóficos - versão eletrônica - ISSN, pp.266-269.

${ }^{38}$ Arquivo Nacional da Torre do Tombo (doravante ANTT). Conde de Linhares. Maço 74/32. "Cartas para D. Mariana de Sousa Coutinho de José Resende Costa", 1813.
}

GOMES, W. S. e CHAVES, C. M. G. Memóría palítica de Jasé de resende Casta Filno: ímašinário do burocrata e Fnconfidêneia wineira (1789-1813). albuquerque: revista de historia. vol. 9, n. 17, jan.-jul. de $2017, \mathrm{p} \cdot 270-285$. 
assevera que a pátria ocupava um lugar central na linguagem do século X VIII e durante a era revolucionária assumia a carga afetiva que o termo nação ainda não possuía. A pátria representava um patrimônio cultural e podia assumir diferentes sentidos de pertencimento. 0 patriotismo, por seu turno, representava mais que um amor à pátria, este assumia o desejo de servi-la, defendêla, atuar em seu progresso e buscar sua liberdade e independência ${ }^{39}$. Essa evidencia fica mais perceptível em outra correspondência de Resende Costa, agora com D. Maria Balbina, em que o conselheiro tece elogios ao seu irmão Principal de Sousa ${ }^{40}$.

\begin{abstract}
Muito metenho alegrado com os princípios que tem as cousas em Portugal: a acçao dePenafiel metransporta. Eu desejava ver meem Portugal; e ao Excelentíssimo Senhor Principal nas suas incessantes vigílias em cuidar na salvação da Pátria; em quanto seu digno e incomparável irmão tração e forma bazes ternas para consolidar a união desde os nossos estabelecimentos formando nos de Brasil recursos imensos para ajudar a Mãe Pátria: a mais lenta e negra inveja esbraveja e se morde: a $N$ ação algum dia Ihe vendera a justiça, que se deve aos seus relevantes serviços e merecimentos: Tenho visto o Tratado do Comércio; de que tantos bens hao de resultar a Monarquia: Deus abençoe e felicite a quem nelle deve tanta parte.41
\end{abstract}

Observando cuidadosamente as falas de Resende Costa à D. Maria Balbina, em outubro de 1810, temos alguns dados importantes para discutir. A noção de pátria remete à monarquia portuguesa, esta responsável por manter a coesão dos Domínios Ultramarinos, ademais é salientada a relevância de uma política de complementariedade em que o Brasil devia prover recursos colaborando com a Mãe Pátria. Destacados esses dois pontos, temos um terceiro, e de grande relevância para aquilo que remete ao imaginário do Conselheiro; sua relação com a monarquia.

Como apresentamos inicialmente, é narrada por Resende Costa, pai efilho, a existência de um projeto para a criação de uma república na Capitania das Minas. A historiografia, talvez por interpretar a sedição eseus personagens fora de seu tempo e espaço concebeu a ideia de república de maneira equivocada. Tratava-se de um sentimento anticolonialista com vistas à revolução, mas que vislumbrava uma

${ }^{39}$ GUERRA, François-Xavier. A nação moderna: nova legitimidade e velhas identidades. In: JANCSÓ, Istvan. Brasil: Formação do Estado e da Nação. São Paulo: Hucitec, 2003, pp.33-46.

40 Atuou como Regente em Portugal enquanto a família Real se encontrava no Brasil entre 9 de agosto de 1810 até 7 de agosto de 1817. Disponível em <http://www.aatt.org/site/index.php?op=Nucleo\&id=1662>. Acesso em 09/05/2016.

41 ANTT. Conde de Linhares. Maço 74/32. “Cartas de José Resende Costa para D. Maria Balbina de Sousa Coutinho", 1810.

GOMES, W. S. e CHAVES, C. M. G. Memória política de josé de resende Casta Filna: inasinário do buracrata e Fnconfidêneia Mineira (1789-1813). albuquerque: revista de histaria. vol. 9, n. 17, jan.-jul. de $2017, \mathrm{p} \cdot 270-285$. 
república local e não global como sugerido no trabalho de Márcio Jardim ${ }^{42}$. Os plutocratas mineiros buscavam que seus interesses imediatos fossem atendidos, e a própria suspensão da derrama terminou por enfraquecer a sedição. A experiência econômica que eles vivenciavam mostrou-se um dos principais elementos, especialmente para que pai filho se envolvessem.

Existia um projeto para pressionar e mostrar à Coroa Portuguesa os problemas que eram enfrentados pela capitania. Os inconfidentes se reuniram acreditando que dado à insatisfação geral com a derrama, a população mineira se mobilizaria de forma conjunta e apoiaria a sedição ${ }^{43}$. 0 fato de que os sediciosos setecentistas buscavam restaurar uma ordem anterior não diminui a relevância do movimento.A Inconfidência Mineira da mesma forma que as diversas revoltas que a antecedeu intensificavam a necessidade de uma reforma profunda no sistema. Algo que aparentemente foi mais bem observado com d. Rodrigo de Sousa Coutinho. A sedição pode não ter delineado com clareza o seu projeto republicano, o que produziu brechas nas interpretações contemporâneas e imprimiu ao movimento algo maior que os seus reais objetivos, todavia foi essencial para despontar o novo cenário que estava sendo desenhado.

É fato que se passaram quase duas décadas desde a descoberta e repressão à sedição, bem como a própria reinserção de Resende Costa, filho, na administração imperial. Todavia, há algo peculiar nos dizeres do conselheiro, e que pode ser enxergado como um "fortalecimento da monarquia", demonstrando que a república outrora ensejada não se distanciava dos padrões da tradição ibérica e a própria percepção de ruptura éequivocada. 0 burocrata considera queas ações de d. Rodrigo produziriam um bem à monarquia, ideias das quais compartilhava. Os primeiros passos da trajetória política de Resende Costa, o filho, pode ter sido marcados pela insurgência contra seus monarcas, contudo, seu retorno a cargos de destaque da burocracia imperial demonstram a transitoriedade das ocorrências no interior Império luso-brasileiro.

Resende Costa, o filho, era um intelectual e defensor das práticas reformistas de d. Rodrigo, com a família real devidamente estabelecida na A mérica Portuguesa e a abertura dos portos às nações amigas, um nexo entre metrópole e colônia era um elemento necessário para o fortal ecimento do Império. 0 sentimento de apreço à nação portuguesa ainda estava fortemente arraigado nos habitantes da A mérica Portuguesa. 0 burocrata, tendo assistido às mudanças adotadas e agora como membro da administração, pode ter enxergado que suas expectativas de outrora

\footnotetext{
42 Para Furtado, a interpretação de Jardim foi pautada em um conceito de República nos moldes contemporâneos, desconsiderando o imaginário e os teóricos que circundavam o século XVIII. FURTADO, João Pinto. op. cit., p. 157.

${ }^{43}$ Maxwell destaca que os inconfidentes esperavam que a derrama fosse imposta em meados de fevereiro. Contando com a inquietação geral do povo e conivência dos dragões, seria instigado o motim. MAXWELL, Kenneth R. op. cit., 402.
}

GOMES, W. S. e CHAVES, C. M. G. Memóría palítica de Jasé de resende Casta Filna: inasinário do burocrata e Fnconfidência Mineira (1789-1813). albuquerque: revista de histaria. vol. 9, n. 17, jan.-jul. de $2017, \mathrm{p} \cdot 270-285$. 
haviam sido atingidas. Observando as novas perspectivas historiográficas e a trajetória de Resende Costa podemos perceber que restaurar a ordem era mais interessante que se levantar contra a Coroa portuguesa.

\section{considerações finais}

A nalisada a trajetória política de Resende Costa Filho e historiografia pertinente observamos a ausência de um projeto unívoco aos inconfidentes, todavia ainda prepondera a noção de que todos os partícipes tinham um mesmo objetivo. A partir desse viés que foram e são produzidos filmes e novelas sobre o tema. As histórias por vezes extrapolam os limites e o imaginário da sedição, solidificando ideias do senso comum e da historiografia do século XIX.N ão se tratam de versões meramente fantasiosas, mas da versão que foi construída e aceita pela sociedade. A âncora de liberdade, assim como o projeto independentista republicano - está incorporada à memória da sedição e, por conseguinte mantém-se ligada à história das Minas. Nesse sentido, não se trata de uma mentira, mas de uma construção histórica e memorialística com a qual é difícil a historiografia duelar. E por esse motivo 0 argumento de Gumbrecht é válido para pensarmos esse trabalho. A capacidade de ensinar da história é o que a legitima como conhecimento científico, mas a relação com a história nos dias atuais é diferenciada. A historiografia torna-se paulatinamente um objeto restrito historiadores, e o passado mesmo que causando interesse e fascínio, tem outras formas de difusão mais atraentes. $O$ que exige a emergência de repensarmos meios de aproximar a historiografia de outras mídias.

Sobre o projeto restaurador, se por um lado o jovem Resende Costa vislumbrou insurgir contra a administração colonial eseus representantes em 1789, anos mais tarde e provavelmente amadurecido pelas experiências, ele pode ter enxergado que seus anseios haviam sido atendidos. Um ol har mais apurado sobre os A DIM, eum novo enfoque historiográfico, permitiram entrever al guns aspectos que ainda não tinham sido contemplados sobre a sedição. A perspectiva contemplada a partir da atuação de Resende Costa Filho endossa a heterogeneidade no interior da Inconfidência Mineira, além da dissonância de interesses. Existiam diferenças acerca da estratificação social dos agentes, suas motivações econômicas, tal como às ideias do sentido último do projeto sedicioso. $O$ sistema colonial passava por uma transição que produziria mudanças substanciais no cenário oitocentista. A vinda da Família Real e o fortalecimento da ideia de um Império luso-brasileiro podem ter significado parte da realização das expectativas do Conselheiro Resende Costa.

GOMES, W. S. e CHAVS, C. M. G. Memória palítica de Jasé de resende Casta Filina: imaśinário do burocrata e Enconfidência mineira (1789-1813). albuquerque: revista de historia. val. 9, n. 17, jan.-jul. de 2017, p. 270-285. 